\title{
Attitudes of Design Students Toward Computer Usage in Design
}

\author{
ŞULE TAŞLI PEKTAŞ and FEYZAN ERKIP \\ Department of Interior Architecture and Environmental Design, Faculty of Art, Design and \\ Architecture, Bilkent University, Ankara, 06800, Turkey
}

\begin{abstract}
The success of efforts to integrate technology with design education is largely affected by the attitudes of students toward technology. This paper presents the findings of a research on the attitudes of design students toward the use of computers in design and its correlates. Computer Aided Design (CAD) tools are the most widely used computer applications in design. An instrument was developed and applied for the first time to relate computer attitude to design field through CAD. Interior architecture undergraduates of Bilkent University participated in the survey. As a result, students' attitudes toward the use of computers in design were found to be positive. A significant gender difference in attitudes toward computers was observed with males having more positive attitudes than females. The results also revealed that students' attitude toward computer usage in design was highly related to their general attitude toward computers, but it was not correlated with their perception of instructors' attitude toward the use of computers in design.
\end{abstract}

Keywords: CAD, computer attitudes, design education, gender differences

\section{INTRODUCTION}

In recent years, the developments in information technology have been changing the practice of both architectural profession and its education. Under competitive market conditions, Computer Aided Design (CAD) is a skill that is increasingly sought after in architectural offices. Practicing architects often value competence in the production of digital presentations, efficiency in the production of construction drawings and ability of collaboration through digital media (Taşl 2001). Moreover, Stevens (1997) claims that due to the massive increase in the number of architecture graduates, an occupation at the lower cadres of architectural jobs, namely, the manual drafter with no architectural education, has disappeared in recent years. They have been replaced by CAD operators probably about half of whom are qualified architects. As a result of all these developments, the profession is continuously forcing schools to enhance CAD teaching in their curricula.

CAD teaching is now a part of curricula in almost every architectural school; however, it seems that the rapid implementation of computers in design education has caught academia unprepared to develop a pedagogy for a digital practice. Studies which focus on the use of CAD in design education are mostly theoretical and/or descriptive in their research approach. Few empirical studies - which test their hypotheses statistically - have been reported in the literature (Hanna \& Barber 
2001). Attitudes of students toward the use of computers in design is one of the neglected issues in that respect. Most of the descriptive studies in this field imply that students have positive attitudes toward computer usage in design, however, a systematic examination of this attitude and its correlates is lacking.

Within this framework, we aim to explore the attitudes of design students toward the use of computers in design with two possible correlates:

1. Attitude toward computers

2. Students' perception of their studio instructors' attitudes toward the use of computers in design.

The students' general perception of studio instructors' reliability has also been investigated to find out if computer attitude differentiates from it. Gender differences across all categories have been considered as an important dimension in this study.

Although there is not much evidence on this specific topic, computer attitudes in general, constitute an ever-developing literature. The main concern for some of the researches is to develop computer attitude scales (Berberoglu \& Calikoglu 1993; Francis 1993 ; Jones \& Clark 1994; Loyd \& Gressard 1984). Identification of components and correlates of computer attitude, and gender differences in terms of attitude toward computers constitute the subject of many studies. Nevertheless, there seems to be no agreement in the literature on what constitutes computer attitude and what its correlates are. For example, Dambrot et al. (1985) reported that computer attitude was related to math anxiety and computer experience among freshman students. Arthur and Olson (1991) employed path analysis to model the relations between computer attitudes, computer experience, and cognitive ability among psychology students. Sigurdsson (1991) examined the relationship between attitudes toward computers and personality characteristics among psychology undergraduates.

The relation between the students' and teachers' attitudes toward computers is one of the controversial issues in computer attitude research. Some researches have suggested a relation between the student and teacher attitudes toward computers. For example, Downes (1993) reported that a good role model, in the form of a classroom teacher who uses computers, leads to more positive attitudes toward computers for secondary school students. On the other hand, there are often differences between students and teachers in their attitudes to information technology (Zoller \& Donn 1993). Smith (1986) showed that teacher computer efficacy scores are significantly and negatively related to that of students. Then, she commented that as students' confidence went up with more exposure to computer classes, apparently teachers' confidence went down. Previous research revealed that studio instructors of the Department of Interior Architecture and Environmental Design (IAED) are not 
very willing to use computer technology in their professional studies (Erkip et al. 1997). They are also reluctant to accept computer drafts in design courses (Basa \& S enyapılı 2005). Thus, we would expect that at the university level, students' attitudes toward the use of computers in design may not correlate with their perception of instructors' attitudes, while their attitudes toward computers in general is a strong correlate of the attitude toward computer use in design.

Many researches on gender differences in computer attitudes showed that male students have more positive attitudes compared to females. For example, Dambrot et al. (1985) found that females held more negative attitudes toward computers, scored lower in computer aptitude, and had less prerequisite math ability and math coursework. Robertson et al. (1995) revealed that male students have more favorable attitudes toward computers than female students do. Shashaani (1997) reported that females were less interested in computers and less confident than males among college students. Mitra et al. (2000) pointed out that females were less positive about computers than males and the use level of computers by females were less frequent in a longitudinal survey of college students. However, some conflicting results have also been reported (Dyck \& Smither 1994; Houle 1996). Mitra et al. (2000) claim that as computers became more popular during the 1990s, more studies began to conclude that there is no significant gender difference in attitude toward computers. Also, one previous research found no significant difference between males and females in their attitudes of 'efficacy' or sense of confidence in ability to use computers (Smith 1986).

Since gender differences in terms of attitudes toward high technology have a strong cultural component (Shashaani 1993), we need to describe the Turkish case. In Turkey, young males and females have strong identification with their parents' traditional gender roles (Kağıtçıbaşı 1982). Studies have indicated that even a university degree did not change women's traditional perceptions of gender roles (Kandiyoti 1982). Furthermore, adolescents tend to view technology and science as the domain of males. The State Institute of Statistics of Turkey (2003) has reported that between 1993 and 2001, more male students enrolled in mathematics and computer science-based higher education programs than females (Figure 1). In the same period, however, the number of female students enrolled in fine and applied arts programs has exceeded that of males (Figure 2). Thus, we would expect a gender difference in attitudes toward computers with males having more positive attitudes than females.

\section{THE RESEARCH}

\section{The research question}

Considering the literature on computer attitudes as reviewed above, this research has been designed around the following question: 


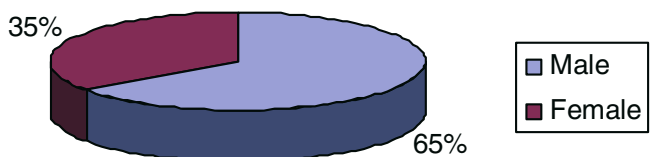

Figure 1. Gender distribution of students enrolled in mathematics and computer science-based higher education programs between 1993 and 2001.

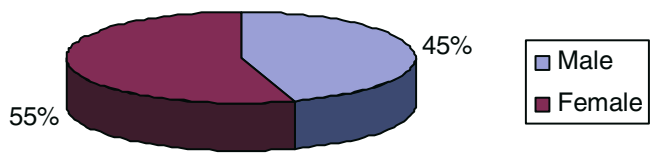

Figure 2. Gender distribution of students enrolled in fine and applied arts programs between 1993 and 2001.

What are the attitudes of interior architecture students toward the use of computers in the design phase of architectural design process?

\section{The hypotheses}

1. Interior architecture students' attitude toward the use of computers in the design phase of architectural design process is positive.

2. Male students' attitude toward the use of computers in design is more positive compared to that of female students.

3. Interior architecture students' attitude toward the use of computers in design correlates with their attitude toward computers.

4. Interior architecture students' attitude toward the use of computers in design does not correlate with their perception of their instructors' attitude toward the use of computers in design.

\section{Methodology}

To test the validity of the hypotheses above, a survey was conducted in the Department of Interior Architecture and Environmental Design (IAED) of Bilkent University. Samples were randomly drawn from the senior students to obtain the largest possible sample size with equal amounts of males and females. Since senior students have taken most of the CAD related courses offered by the department; their knowledge on CAD was assumed to be sufficient for evaluating CAD terminology (See Appendix A for the list and content of CAD courses offered in the department). A total of 62 senior students participated in the survey (31 males and 31 females). All of the subjects' responses were complete and used in the evaluation. 
A questionnaire that contained four categories of variables was used in this study. These four categories were defined as (1) general attitude toward computers, (2) attitude toward the use of computers in design, (3) perception of instructors' attitude toward the use of computers in design and (4) general perception of instructors' reliability. A five point Likert scale was used for the evaluation of the statements in the questionnaire, and the responses to the statements were coded as follows: Strongly disagree $=1$, Disagree $=2$, Undecided $=3$, Agree $=4$ and Strongly agree $=5$.

The questionnaire contained 20 items, a half of which was worded positively, and the other half was worded negatively to test the validity of responses. The order of statements in the questionnaire follows the order of categories in such a way that one statement from each category was located as every 4 th statement. In this way, it was expected to prevent bias that may occur due to consecutive statements from the same category. Before the application of the questionnaire to the whole sample, a pilot study with 20 students was conducted to test the instrument. In the pilot study, the alpha reliability coefficients were calculated for each category. Before calculating the alpha, the values of the responses to the negative statements were reversed in order to maintain a unified direction on the scale where high values represent positive attitudes and vice versa. The Alpha reliability coefficients for general attitude toward computers, attitude toward the use of computers in design, the perception of instructors' attitude toward the use of computers in design and the general perception of instructors' reliability were $0.78,0.85,0.82$ and 0.80 , respectively, indicating each category is internally consistent. Items from the previously validated instruments were used in the general computer attitude category (Shashaani 1993). Validation of the other groups of statements was established in a correlation of objectives related to courses with computer content and test items.

The survey was carried out by the authors. The questionnaire was applied in one session in the class to prevent bias and communication between students. Instructors did not take any part in the research arrangement also to avoid bias. Students were given sufficient time to complete the questionnaires and they were assured that they would remain anonymous.

Descriptive statistics and $t$-tests were applied for the whole sample and for males and females separately. Pearson product moment correlation coefficients were also calculated between the related categories. The SPSS statistical software package (Release 10.0) was used in the statistical analysis. The Alpha reliability coefficients for attitude toward computers, attitude toward the use of computers in design, the perception of instructors' attitude toward the use of computers in design and the general perception of instructors' reliability were $0.84,0.83,0.78$ and 0.76 , respectively. These coefficients indicate high reliability of the results. 


\section{RESULTS}

The subjects' attitude toward computers was found significantly positive (Table I). Across all the statements in Table I, females scored higher on the negative statements and lower on the positives than males. The independent samples $t$-test yielded a significant gender difference in the attitude toward computers. However, the difference was less for students' eagerness to learn more about computers $(X=4.77$ for males and $X=4.32$ for females). This may indicate that students were motivated enough to demand more computer knowledge regardless of their computer attitudes.

The subjects' attitude toward the use of computers in design was also found to be positive supporting the hypothesis 1 (Table II). Only for the statement 9, 'I look forward to use computers while producing design concepts' the total mean is very close to 3 , which indicates a neutral response. However, males tended to agree with the statement $(X=3.65)$ more, whereas females' mean is much lower $(X=2.26)$. Although males responded positively to this statement, the degree of affirmation is lower than that of the other statements in this group. This suggests that the subjects were not as enthusiastic about using computers while producing design concepts as they were for other aspects of computer use in design. The results supported the hypothesis 2 and showed that male students have more positive opinions about the use of computers in design.

The subjects' perception of their instructors' attitude toward computers were found to be negative (Table III). A significant gender difference was found on the statements 11, 'My studio instructors believe that computers kill creativity' and 12, 'It seems to me that my studio instructors are interested in computers' with females having a more positive perception of their instructors' attitude toward the use of computers in design.

Students' general perception of their instructors' reliability is found to be highly positive (Table IV). It was also observed that female students rely on their instructors more than males do.

Correlation coefficients were calculated between the two pairs of categories:

1. Attitude toward computers - attitude toward the use of computers in design

2. Perception of instructors' attitude toward the use of computers in design - attitude toward the use of computers in design.

Although there were significant correlations between students' attitudes toward computers and their attitudes toward the use of computers in design (Table V), we found only one significant correlation between students' attitudes toward the use of computers in design and their 


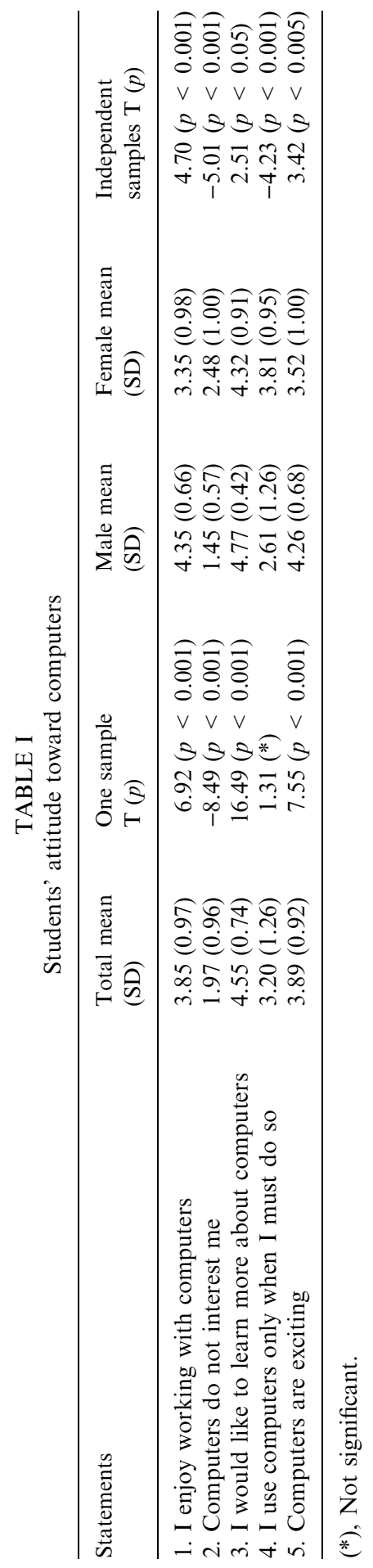




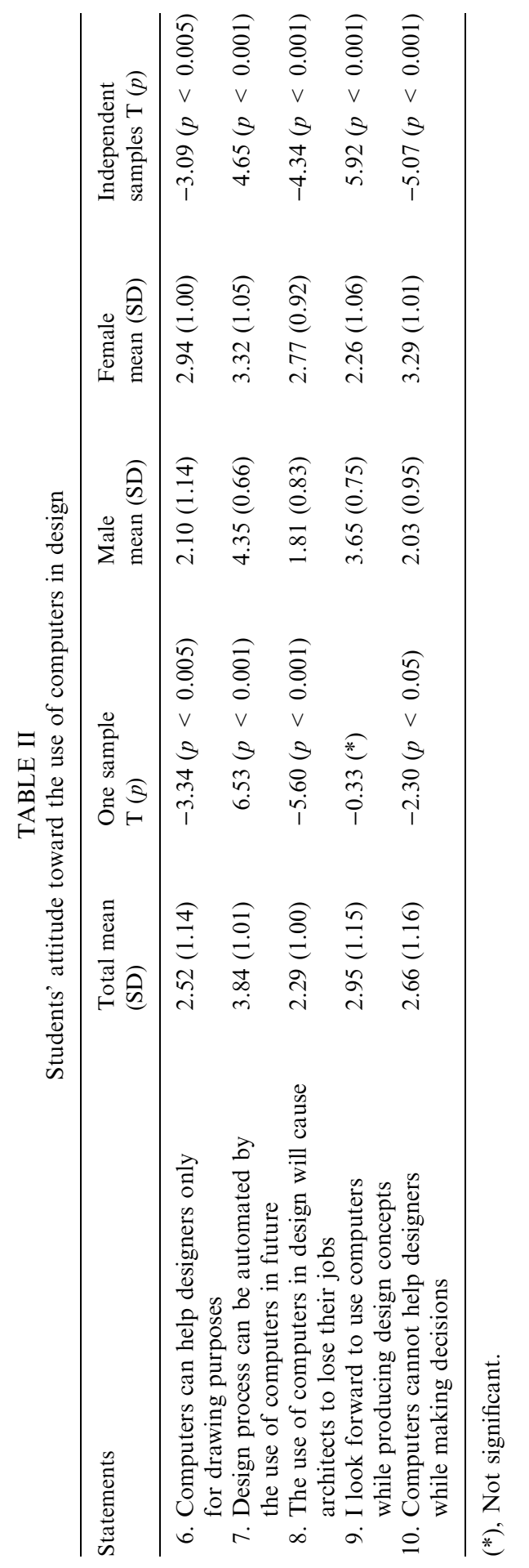




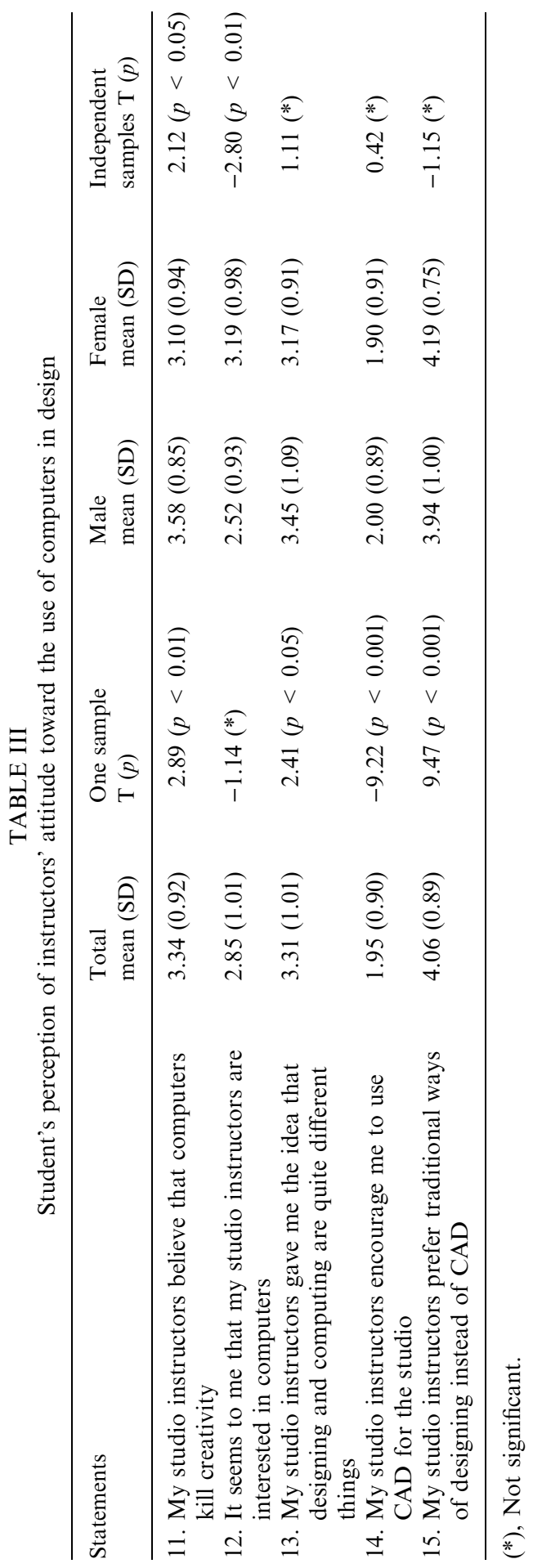




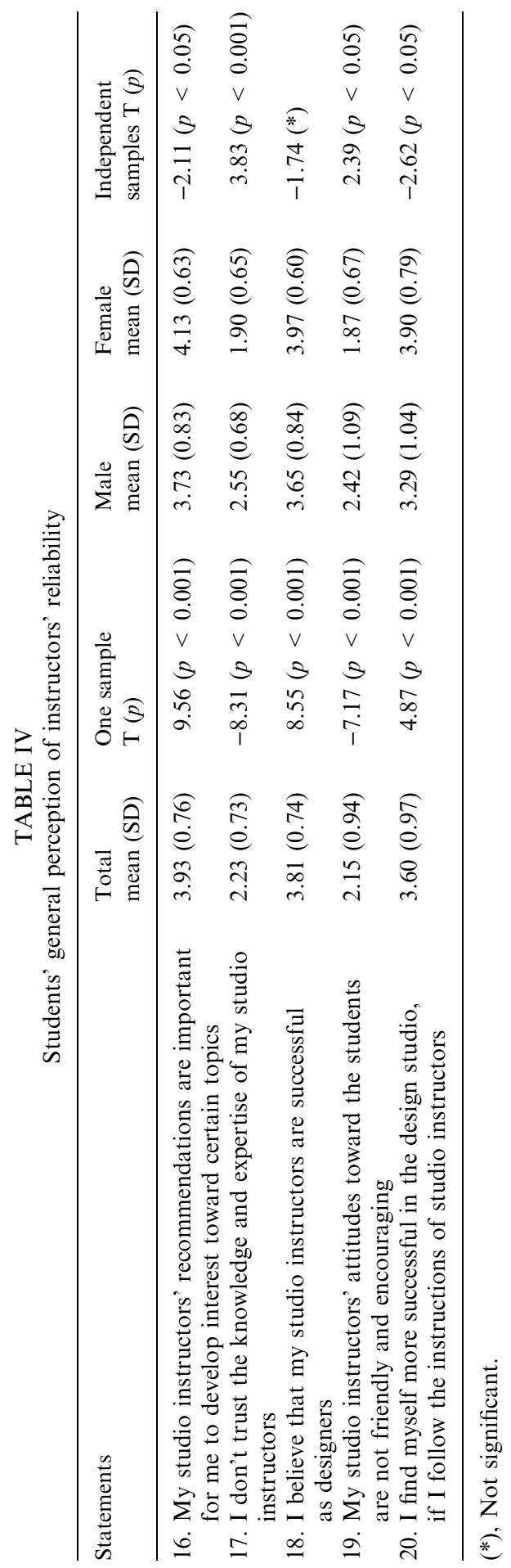




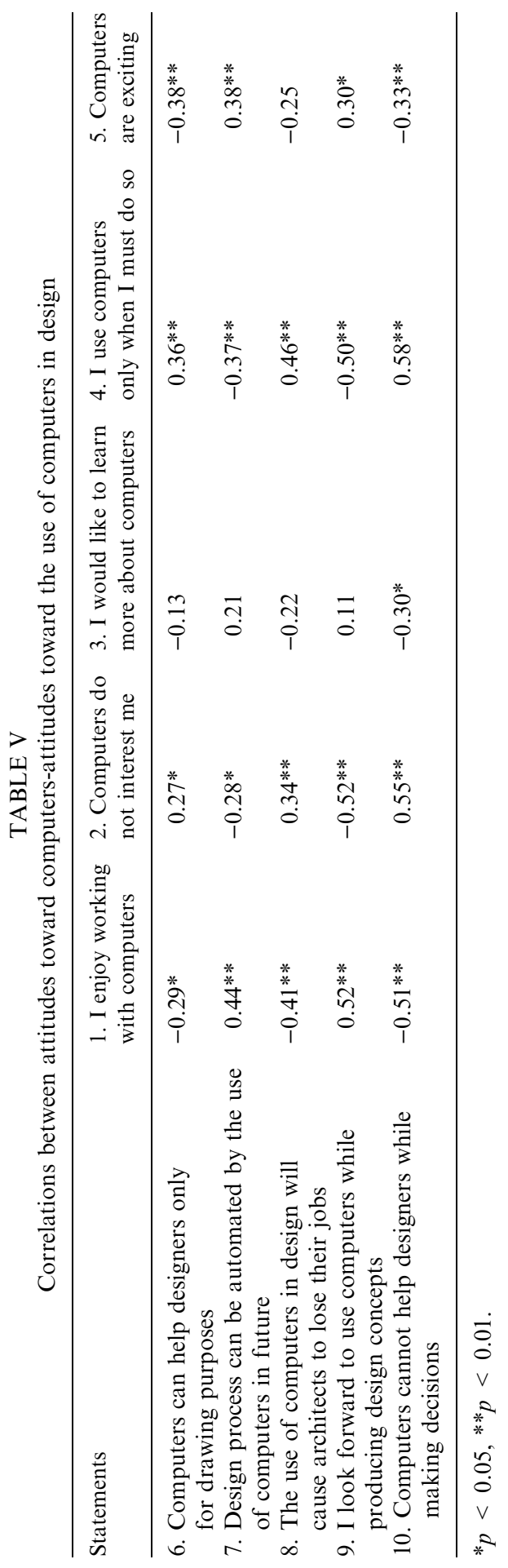


perception of the instructors' attitude (between the statements 9 and 15; $r=-3.32, p<0.05$ ). These findings supported our hypotheses 3 and 4 .

We also calculated correlations between students' attitudes toward the use of computers in design and their perception of the instructors' attitude for males and females separately. We found only one significant correlation in the female group (for the statements 9 and $14 ; r=0.51$, $p<0.01)$. However, in the male group there were three significant correlations. The statements 6,9 and 10 in this group are correlated with the statement 12, 'It seems to me that my studio instructors are interested in computers' $(r=-0.37,0.41,-0.55$ respectively; $p<0.05)$. This suggests that perception of instructors' interest in computers is more influential on students' computer attitudes than the other dimensions of the perceived instructors' attitude.

\section{DISCUSSION AND CONCLUSION}

The results of this study indicate several aspects of students' attitudes toward the use of computers in design. It is found that this attitude correlates with their attitude toward computers in general. However, there is no correlation between this attitude and students' perception of their instructors' attitude. This result is interesting because we also found that students' general perception of their instructors' reliability is very positive. There seems to be a gap between the instructors and students in terms of computer attitudes supporting the findings of Robertson et al. (1995) and Smith (1986). These researchers discuss the reasons for the negative attitudes of instructors toward computers. Smith (1986) argues that older instructors may feel less competent because they have not 'grown up' with computers. Robertson et al. (1995) mention three possible explanations for the unfavorable attitudes of instructors toward computers. One of them is the conservatism, and the other is the anxiety of instructors caused from having to introduce more innovation to their teaching. The third possibility is that the staff and students may have different perceptions about computers. The students may see them as machines to be used or even as high-tech tools and the teachers may perceive them in context, for example as potential pedagogical tools that they are not adequately prepared to use.

In fact, unlike most design offices which depend only on computerized drafting after the preliminary design stage - largely due to its time and energy saving nature - there seems to be a tension between traditional design tools and CAD in schools. Besides the financial and technological limitations, the situation also stems from the studio instructors' reluctance to incorporate computers with design teaching. Possible reasons for this reluctance include the lack of proficiency of the instructors in computers (Basa \& S enyapılı 2005), focusing only on the 'conceptual' phase of architectural design process and seeing the existing CAD tools 
as merely drafting rather than design tools (Hanna \& Barber 2001) and fearing that supporting CAD in design education will lead to the loss of hand drawing skills in time (Shu 2000). The exploration of these issues may constitute the content of further research.

Students' general attitude toward computers is found highly positive. This can be explained by several factors. High socioeconomic status (Miura 1987) and access to computers (Gattiker \& Hlavka 1992; Levin \& Gordon 1989; Loyd \& Gressard 1984) were defined as important factors to construct positive attitudes toward computers. According to a report by The Scientific and Technological Research Council of Turkey (TUBITAK), the percentage of computer ownership among Turkish households is $12.3 \%$ in 2000. A similar research made in 1997 reports this amount as $6.5 \%$, thus it is seen that the amount of computer ownership at homes doubled in three years. When computer ownership percentages are investigated for different income groups, it is observed that computer ownership percentage reaches to $64.7 \%$ in the high income group, while it is $8.2 \%$ in the lower-middle and $2 \%$ in the low income group (TUBITAK 2001). Bilkent University is the first private university in Turkey and the students come predominantly from high income families. In the light of the argument presented above, we may assume that our sample group is most likely to have a computer access also at home. This may be one of the reasons for their positive attitudes toward computer use in design.

Another point mentioned by Robertson et al. (1995) is that the concept of 'the computer' is becoming so much a part of culture that the majority of young people expect to be able to understand them and enjoy using them. This observation seems to be valid for design fields where integration of computers has been strongly pursued. Thus, it is likely that interior architecture undergraduates are 'forced' to develop positive attitudes toward using computers in design for practical purposes. This idea was supported by our findings on students' attitude toward computers. Although there was no statistically significant evidence to reject the statement 4, 'I use computers only when I must do so' $(X=3.20)$, the responses to the statement 3, 'I would like to learn more about computers' are significantly positive for both groups $(X=4.77$ for males and $X=4.32$ for females).

The study revealed a significant gender difference in computer attitudes among interior architecture undergraduates with males having more positive attitudes than females. Our findings are supported by comparison of gender distribution in an obligatory CAD course (Figure 3) and two elective CAD courses (Figure 4) all at the third year level. Although the amount of male and female students is almost equal in the obligatory course, female students are less willing to take a CAD course as an elective.

It is also found that girls are more reliant on their instructors. This finding supports Yildırım (1997) who showed that among Turkish adolescents, girls placed higher importance on school in their hierarchy 


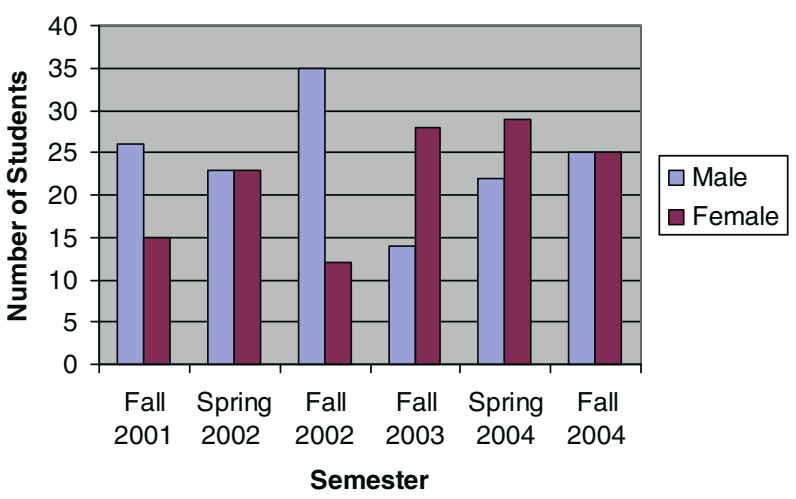

Figure 3. Gender distribution of students in the third year obligatory CAD course (IAED 311).

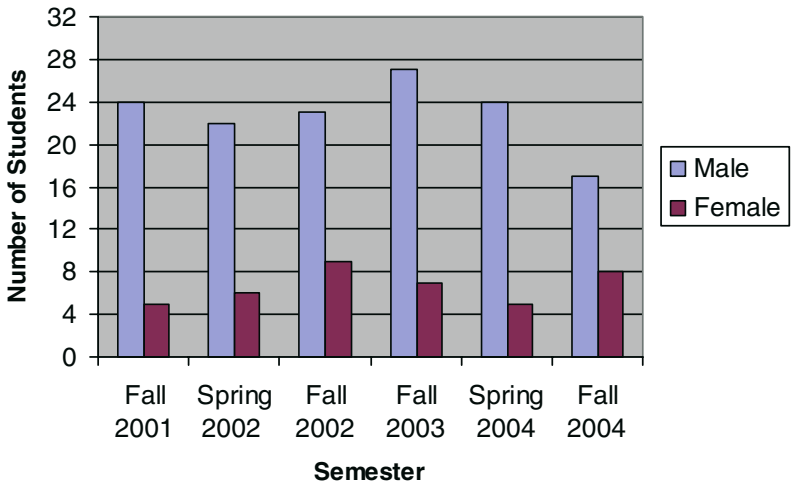

Figure 4. Gender distribution of students in the two elective CAD courses (IAED 315 and 316) Note: Spring 2003 semester is not included in the analysis, because IAED 316 was not offered in that semester.

of life contexts compared to boys did. Considering the girls' reliance on their instructors, one would expect that they are more likely to reflect the instructors' negative attitude toward the computers in design. However, we did not find substantial correlations between female students' attitude toward computer usage in design and their perception of the instructors' attitude. This suggest that other factors such as gender stereotyping, parental influence, computer experience, and math aptitude should be investigated in further research in order to explain gender differences in design students' computer attitudes.

As a result of our findings, we recommend that institutions of (interior) design education should regard the use of computers as a socio-cultural rather than merely a technical issue. This approach may lead to create more positive attitudes toward the use of computers in 
design among both the instructors and the students. Gender differences in computer attitudes could be reduced to a minimum via careful consideration and handling of these issues in design curricula. In order to bridge the gap between the educators and students in terms of computer attitudes, we also suggest that design instructors, not necessarily being experts on the subject, should understand the potentials of computer use in design studios. Previous experience showed that team teaching and parallel exercises can be helpful for such integration (Taşlı 2001).

Finally, it should be emphasized that the scope and meaning of the use of computers in design is subject to rapid change due to developments in computer technology. Mitra et al. (2000) explains that in the researches on computer attitude, 'computer use' have been defined loosely without discriminating and categorizing different uses. They criticize this approach for not responding to expanded computer applications. In view of this problem, our study has attempted to focus on a very specialized use of computers in education, namely computer use in design. Considering the lack of appropriate tools for attitude measurement in this particular field, it is expected to contribute in that respect. The authors hope that this research will form a basis for future studies, which will aim at a deeper analysis of students' attitudes toward different computer applications in design.

\section{APPENDIX A}

TABLE VI

The CAD Courses Offered in the Department of IAED

\begin{tabular}{|c|c|}
\hline Course name & Course content \\
\hline $\begin{array}{l}\text { IAED } 212 \text { Computers } \\
\text { and Geometry* }\end{array}$ & $\begin{array}{l}\text { This course is designed to introduce basic geometric } \\
\text { concepts, hardware and software usage and the basic } \\
\text { skills to produce 2D CAD drawings. It is the } \\
\text { prerequisite of IAED } 311 \text {. }\end{array}$ \\
\hline IAED 311 Computer & In this course, students learn to use the computer \\
\hline Aided Design* & $\begin{array}{l}\text { as a } 3 \mathrm{D} \text { modeling tool. Throughout the semester they } \\
\text { design and draw several } 3 \mathrm{D} \text { objects. }\end{array}$ \\
\hline IAED 315 Computerized & This course focuses on advanced usage of computer \\
\hline Presentation Techniques & programs for representation of the student projects. \\
\hline IAED 316 Computer & In this course, students produce design projects \\
\hline Applications & by the help of various application programs. \\
\hline
\end{tabular}

*Obligatory course.

\section{REFERENCES}

Arthur, W. \& Olson, E.: 1991, Computer Attitudes, Computer Experience and Their Correlates: An Investigation of Path Linkages, Teaching Psychology 18, 51-54. 
Basa, I. \& Şenyapil1, B.: 2005, 'The (In)secure Position of the Design Jury towards Computer Generated Presentations', Design Studies (in press).

Berberoglu, G. \& Calikoglu, G.: 1993, Factorial Validity of the Turkish Computer Attitude Scale, Studies in Educational Evaluation 19, 257-263.

Dambrot, F. H., Watkins-Malek, M. A., Silling, S. M., Marshall, R. S. \& Garver, J. A.: 1985, Correlates of Sex Differences in Attitudes toward and Involvement with Computers, Journal of Vocational Behavior 27, 71-86.

Downes, T.: 1993, Student Teachers' Experiences in Using Computers during Teaching Practice, Journal of Computer Assisted Learning 9, 17-33.

Dyck, J. L. \& Smither, J. A.: 1994, Age Differences in Computer Anxiety: The Role of Computer Experience, Gender, and Education, Journal of Educational Computing Research 10, 239-248.

Erkip, F., Demirkan, H. \& Pultar, M.: 1997, 'Knowledge Acquisition for Design Education': 1997, in J. S. Smith (ed.), Proceedings of the International Conference on Design and Technology Educational Research and Curriculum Development, pp. 126-132, Loughborough University, Loughborough, UK.

Francis, L. J.: 1993, 'Measuring Attitude toward Computers among Undergraduate College Students: The Affective Domain', Computers and Education 20, 251-255.

Gattiker, U. E. \& Hlavka, A.: 1992, Computer Attitudes and Learning Performance: Issues for Management Education and Training, Journal of Organizational Behavior 13, 89-101.

Hanna, R. \& Barber, T.: 2001, An Inquiry into Computers in Design: Attitudes before Attitudes After, Design Studies 22, 255-281.

Houle, P. A.: 1996, Toward Understanding Student Differences in a Computer Skill Course, Journal of Educational Computing Research 14, 25-48.

Jones, T. \& Clark, V. A.: 1994, A Computer Attitude Scale for Secondary Students, Computers and Education 22, 315-318.

Kağıtçıbaşı, Ç.: 1982, 'Introduction', in C. Kağıtçıbaşı (ed.), Sex Roles, Family and Community in Turkey (pp. 1-32), Indiana University Turkish Studies 3.

Kandiyoti, D.: 1982, 'Urban Change and Women's Roles in Turkey: An Overview and Evaluation', in C. Kağıtçıbaşı (ed.), Sex Roles, Family and Community in Turkey (pp. 101120), Indiana University Turkish Studies 3.

Levin, T. \& Gordon, C.: 1989, Effect of Gender and Computer Experience on Attitudes toward Computers, Journal of Educational Computing Research 5(1), 69-88.

Loyd, B. H. \& Gressard, C. P.: 1984, Reliability and Factorial Validity of Computer Attitude Scales, Educational and Psychological Measurement 44, 501-505.

Mitra, A., Lenzmeier, S., Steffensmeier, T., Avon, R., Qu, N. \& Hazen, M.: 2000, Gender and Computer Use in an Academic Institution: Report from a Longitudinal Study, Journal of Educational Computing Research 23, 67-84.

Miura, T.: 1987, Gender and Socioeconomic Status Differences in Middle School Computer Interest and Use, Journal of Early Adolescence 7, 243-253.

Robertson, S. I., Calder, J., Fung, P., Jones, A. \& O'Shea, T.: 1995, Computer Attitudes in an English Secondary School, Computers and Education 24, 73-81.

Shashaani, L.: 1993, Gender-Based Differences in Attitudes toward Computers, Computers and Education 20, 169-181.

Shashaani, L.: 1997, Gender Differences in Computer Attitudes and Use among College Students, Journal of Educational Computing Research 16, 37-51.

Shu, E. H. A.: 2000, Touch versus Tech: Hand-drawn or Computer Rendered Techniques, Architectural Record 188(2), 170-173.

Sigurdsson, J. F.: 1991, Computer Experience, Attitudes toward Computers and Personality Characteristics in Psychology Undergraduates, Personality and Individual Differences 12, 617-624.

Smith, S. D.: 1986, Relationships of Computer Attitudes to Sex, Grade Level and Teacher Influence, Education 106, 338-344.

Stevens, G.: 1997, Reflections of an Apostate CAD Teacher, Journal of Architectural Education 51(1), $78-80$ 
Taşl1, S.: 2001, 'Bridging the Gap between Theory and Practice in Architectural Education: The Case of CAAD Teaching': 2001, in N. Çağlar (eds.), Proceedings of the 19th EAAE International Conference, Re-integrating Theory and Design in Architectural Education, pp. 203-209, Gazi University, Ankara, Turkey.

The Scientific and Technological Research Council of Turkey (TUBITAK): 2001, Bilgi Teknolojileri Yaygınlık ve Kullanım Araştırması - 2000 (The Research on Diffusion and Use of Information Technologies), TUBITAK, Ankara.

The State Institute of Statistics: 2003, '2002 Statistical Yearbook of Turkey', DIE Press, Ankara.

Yildırım, A.: 1997, Gender Role Influences on Turkish Adolescents' Self-Identity, Adolescence 32, 217-231.

Zoller, U. \& Donn, S.: 1993, Computer Inclination of Students and Teachers in Relation to Their STS Views, Educational Computing Research 9, 45-49.

\section{BIOGRAPHIES OF THE AUTHORS}

Dr. Sule Taşl1 Pektas is an instructor at the Department of Interior Architecture and Environmental Design, in Bilkent University, Turkey. Her main areas of interest are computer-aided architectural design and design methods. Dr. Feyzan Erkip is an associate professor at the Department of Interior Architecture and Environmental Design, in Bilkent University, Turkey. Her main area of interest is environment - behavior studies and urban issues. 